\title{
What is Wrong with Nimbys? \\ Renewable Energy, Landscape Impacts and Incommensurable Values
}

\author{
ANNE SCHWENKENBECHER \\ Philosophy Program \\ Murdoch University \\ Murdoch, Western Australia 6150 \\ Email: a.schwenkenbecher@murdoch.edu.au
}

\begin{abstract}
Local opposition to infrastructure projects that implement renewable energy (RE), such as wind farms, is often strong even if state-wide support for RE is strikingly high. The slogan 'Not In My Backyard' (NIMBY) has become synonymous for this kind of protest. This paper revisits the question of what might be wrong with those who are NIMBYs about RE projects, and how best to address them. I will argue that local opponents to wind farm (and other RE) developments do not necessarily fail to contribute their fair share to producing a desirable public good (clean energy). In fact, with landscape concerns being at the heart of much protest, the question of fair burden distribution becomes sidelined: landscape impacts cannot be distributed nor compensated for. Protests may be attempts to express a true conflict of (incommensurable) values. Understanding them as such will help us better address NIMBY concerns and overcome such opposition through ensuring procedural justice.
\end{abstract}

\section{KEYWORDS}

Renewable energy, landscape values, non-standard accounts of rationality, NIMBY, climate change, value incommensurability

\section{INTRODUCTION}

A frequent phenomenon with regard to renewable energy (RE) infrastructure projects such as wind farms is that local opposition is strong even if state-wide support is strikingly high. In the UK, for example, public support for wind energy is at eighty per cent, but only twenty-five per cent of wind power capacity 
is commissioned (Bell et al., 2005: 460). This would suggest that opposition to RE projects such as wind turbines is, by and large, not motivated by objections to wind energy or renewable energy as such. Rather, local resistance regularly focuses on the specific project proposed, with protesters preferring RE plants not to be built in their backyard. Many of those who oppose local renewable energy projects seem to do so because these would be built in their vicinity, or virtually in their backyard. The slogan 'not in my backyard' (NIMBY) has become synonymous with local communities' resistance to such developments.

For the purpose of this paper, I take the term NIMBY to encompass all those protesters against infrastructure projects $(X)$ whose first preference out of a set of preferences is that a particular project be realized, but not in their immediate vicinity (metaphorically speaking, their 'backyard'). The term NIMBY, as I use it here, includes both 'weak' and 'strong' NIMBYs:

Table 1. Preferences of NIMBYs. ${ }^{1}$

\begin{tabular}{|l|l|l|}
\hline 1st preference: & \multicolumn{2}{|c|}{$X$ is built, but not in my backyard. } \\
\hline & Strong NIMBY & Weak NIMBY \\
\hline 2nd preference: & $X$ is not built at all. & $X$ is built in my backyard. \\
\hline 3rd preference: & $X$ is built in my backyard & $X$ is not built at all. \\
\hline
\end{tabular}

While there may be protesters who reject a project in question altogether, that is, wherever it is built - as is the case with many protesters against nuclear power - the term 'NIMBY' is normally reserved for those who do not reject a project as such, but only oppose its realization in their vicinity. ${ }^{2}$ It will usually not be possible to determine whether a particular NIMBY is of the strong or the weak kind, so I will not focus on this distinction here. For my purposes, a NIMBY is someone who leads or participates in campaigns aimed at preventing particular infrastructure construction projects in their vicinity, including RE projects. The immediate and central aim of NIMBY campaigns is to prevent such projects from going ahead.

This paper revisits the question of what might be wrong with those who are NIMBYs about RE projects, with a view to successfully addressing their

1. This definition is similar to Feldman and Turner's definition of 'genuine' NIMBYs in their 2010 paper, and identical to the one they use in their 2014 paper. They do not cover 'weak' NIMBYs, in contrast to Crozier and Hajzler (2010), who seem to cover only 'weak' NIMBYs. I think it is important to include both sub-types, seeing that their (shared) first preference is the most characteristic feature of NIMBYs.

2. See, for instance, Hermansson: 'NIMBY is described as opposition against something one believes to be good for society at large: something that one would not like to be without, like railways and rehabilitation centres' (2007: 25). 
concerns while implementing a clean energy regime. ${ }^{3}$ The first two sections discuss different ways of construing the wrongness of NIMBYs, showing that it is not clear that we are faced with a type of prisoner's dilemma, that they are free-riders on a public good, or that they necessarily fail to contribute their fair share to a collective endeavour. The upshot of Section Two will be that some of the burdens imposed on local residents - landscape impacts - simply cannot be distributed nor compensated for. Section Three suggests that protesters might be attempting to express a conflict between incommensurable values, and it proposes a variety of ways to address such conflicts. The upshot of the discussion is that such value conflicts are best resolved through stakeholder engagement and adhering to good standards of procedural justice.

\section{NIMBYS, FREE-RIDING AND PRISONER'S DILEMMAS ${ }^{4}$}

Frequently, NIMBYs are regarded as unfair and selfish; this is especially the case where there is a strong consensus about the general societal importance of the developments in question, as is often the case with RE projects. Derek Bell et al. have argued that NIMBYs' opposition to infrastructure projects that the general public - in principle - approve of, such as wind farms, reflects a particular kind of collective-action problem. They argue that opposition to wind farms is individually rational while it is collectively rational to have renewable energy:

In a multi-person prisoner's dilemma it is collectively rational for the public good (wind energy) to be produced, but it is individually rational for each individual to 'free-ride' on the contributions of others (not have wind energy in their area). The individual's contribution to the public good (a few megawatts of wind energy from the local wind farm) is negligible, while the cost of making that contribution may be considerable. $(2005: 465)^{5}$

Bell et al. characterise NIMBYs as akin to defecting agents in a prisoner's dilemma and as free-riders. Is NIMBYism a kind of prisoner's dilemma? Here is the pay-off matrix for a two-person prisoner's dilemma game where $\mathrm{T}>\mathrm{R}$ $>\mathrm{P}>\mathrm{S}$.

3. I use 'clean' energy and 'renewable' energy synonymously here, though there are some non-renewable technologies that are usually counted as 'clean', such as carbon capture and storage. My use of 'clean' energy does not include these fossil-fuel based technologies, but only energy from renewable sources such as wind and solar.

4. I am grateful to David Butler for helpful comments on an earlier draft of this section.

5. See also the discussion in Hermansson (2007: 24ff.). 
ANNE SCHWENKENBECHER

Table 2. Pay-off matrix.

\begin{tabular}{|l|c|c|}
\hline & Player 2 co-operates & Player 2 defects \\
\hline Player 1 co-operates & Reward/Reward & Sucker/Temptation \\
& $\mathrm{R} / \mathrm{R}$ & $\mathrm{S} / \mathrm{T}$ \\
\hline Player 1 defects & Temptation/Sucker & $\begin{array}{c}\text { Punishment/Punishment } \\
\text { T/S } / \mathrm{P}\end{array}$ \\
\hline
\end{tabular}

Both the weak and the strong NIMBY prefer that wind farms be built, but they prefer not to contribute to the good of renewable energy. Let us use a massively simplified scenario where in order to provide a political community $X$ with clean energy, two wind farms have to be built. $X$ consists of only two towns, our two 'players' in this game. Either both towns have one wind farm each in their vicinity, or one town hosts both wind farms, or neither of them has any wind farm at all. In order for that scenario to have the structure of a prisoner's dilemma, it would have to be the case that the people of each town prefer if both wind farms are located near the other town (Temptation). Their second preference would be for them to host one wind farm each (Reward), which is better than having no wind farm at all (Punishment). The worst case for each town is to have both wind farms in their vicinity while the other town has none (Sucker).

Each individual player has a reason to defect, as a way of minimising her risk of being the 'sucker' in the game. The best outcome for her is to defect while the other co-operates (Temptation). Given the awareness that this is the best outcome for the other player, too, 'defecting' will also prove safer if the other player chooses not to co-operate. Defecting is the dominant strategy: it will leave a player better off, regardless of what the other player does. N-player public-goods games are based on prisoner's dilemma games in that the overall benefit is highest if everybody contributes, but individual benefit is highest if everybody else contributes except oneself. Individuals then have a reason to free-ride on the others' contributions. With everybody adopting this strategy, the public good is diminished to the point where no-one benefits, even individually.

But are NIMBYs like the 'tempted' player in our two-player prisoner's dilemma or in an $n$-player public goods game? This would very much depend on the value they attach to the two main factors at play: the provision of RE and the absence of wind turbines in their vicinity. We introduced NIMBYs as agents whose first preference is that RE projects such as wind farms be realised as long as this does not impact on their quality of living. Their preferred outcome, one might say, is to defect while others co-operate. This resembles the 'temptation' (T) payoff in prisoner's dilemmas. For the strong NIMBY, though, the second preference would not be to co-operate $(\mathrm{R})$, but to $\operatorname{defect}(\mathrm{P})$. 
This is because the strong NIMBY attaches great value to an absence of wind farms in her vicinity: she prefers to defect, regardless of what others do. Let us assume that between the two remaining scenarios she has a preference for the one where all co-operate over the one where she is the only one who does. That is, the strong NIMBY prefers 'reward' (R) over 'sucker' (S). Their preference structure is: $\mathrm{T}>\mathrm{P}>\mathrm{R}>\mathrm{S}$. This is not the preference structure of players in a prisoner's dilemma.

But would a game involving strong NIMBYs have the same dominant strategies as a prisoner's dilemma? Below I have chosen exemplary payoffs for a game involving a strong NIMBY and a co-operative non-NIMBY with a sense of justice, meaning that she prefers equal contributions (R) to the two scenarios where only one contributes $(\mathrm{T} / \mathrm{S})$, but she is neutral between the two cases of unilateral contribution. To the co-operative non-NIMBY having no wind farm is the worst case, though. Her payoff structure is: $\mathrm{R}>\mathrm{T}=\mathrm{S}>\mathrm{P}$.

Table 3. Exemplary payoffs (strong NIMBY and co-operative non-NIMBY).

\begin{tabular}{|l|c|c|}
\hline & Non-NIMBY co-operates & Non-NIMBY defects \\
\hline Strong NIMBY co-operates & $\mathbf{0} / \mathbf{1 0 0}$ & $\mathbf{- 5 0 / 2 5}$ \\
& $\mathrm{R} / \mathrm{R}$ & $\mathrm{S} / \mathrm{T}$ \\
\hline \multirow{2}{*}{ Strong NIMBY defects } & $100 / 25$ & $\mathbf{2 5 / - 5 0}$ \\
& $\mathrm{T} / \mathrm{S}$ & $\mathrm{P} / \mathrm{P}$ \\
\hline
\end{tabular}

If the strong NIMBY encounters such a fairness-loving impartial non-NIMBY, RE developments are likely to go ahead: the strong NIMBY will defect, but the non-NIMBY's dominant strategy will be to co-operate (as long as she does not mind too much being the sucker).

What about our weak NIMBY? In contrast to the strong NIMBY, the weak NIMBY prefers co-operating to having no wind farms at all (P). So she prefers both 'reward'(R) and 'sucker' (S) to 'punishment' (P). Let us assume that she prefers the scenario where all contribute $(\mathrm{R})$ to the one where only she contributes (S). We arrive at the following payoff structure for the weak NIMBY: $\mathrm{T}$ $>\mathrm{R}>\mathrm{S}>\mathrm{P}$. This payoff structure is also different from that of the prisoners.

The exemplary payoffs for being the sucker are still higher than those for 'punishment', because even though the weak NIMBY does not want a wind turbine in her backyard, she prefers this to having no wind turbines at all. Here is what a game between the weak NIMBY and the co-operative non-NIMBY might look like: 


\section{ANNE SCHWENKENBECHER}

Table 4. Exemplary payoffs (weak NIMBY and co-operative non-NIMBY).

\begin{tabular}{|c|c|c|}
\hline & Non-NIMBY co-operates & Non-NIMBY defects \\
\hline Weak NIMBY co-operates & $\begin{array}{c}50 / 100 \\
R / R\end{array}$ & $\begin{array}{l}0 / 25 \\
\mathrm{~S} / \mathrm{T}\end{array}$ \\
\hline Weak NIMBY defects & $\begin{array}{c}100 / 25 \\
\mathrm{~T} / \mathrm{S}\end{array}$ & $\begin{array}{c}-50 /-50 \\
P / P\end{array}$ \\
\hline
\end{tabular}

The non-NIMBY's dominant strategy is to co-operate, while the weak NIMBY does not have a dominant strategy. If she figures that the non-NIMBY will usually co-operate, she would usually choose to defect. Hence the likely outcome for this kind of conflict is the same as for the one involving strong NIMBYs.

Of course, it is perfectly possible that some NIMBYs have preferences akin to those of the prisoners, that is, that they prefer 'punishment' to being the 'sucker'. It would point out though that this prisoner-like NIMBY has mildly inconsistent preferences: if she really thinks that RE is important, she should prefer $\mathrm{S}$ to $\mathrm{P}$. If she really thinks that justice is important, she should prefer $\mathrm{R}$ to T. Hence, I think that the weak NIMBY is more consistent than the prisonerlike NIMBY, who likes to take advantage of others but then defects rather than allowing others to take advantage of her. But people do not always have consistent preferences and we should not exclude the third NIMBY-type. Let us call her the 'ambivalent NIMBY'.

The ambivalent NIMBY is really in favour of clean energy and wind farms, but she also likes getting a good deal. If she had the choice between having wind farms in her vicinity or not, she would choose not to: $\mathrm{T}>\mathrm{R}$ and $\mathrm{T}>\mathrm{S}$. If she must have them in her vicinity, she prefers that others make a sacrifice, too: $\mathrm{R}>\mathrm{S}$. If she finds herself to be the only one making a sacrifice her sense of injustice overpowers her desire for clean energy: $\mathrm{P}>\mathrm{S}$. Renewable energy - yes - but not at her cost alone:

Table 5. Preferences of the ambivalent NIMBY.

\begin{tabular}{|l|l|}
\hline 1st preference: & $X$ is built, but not in my backyard. \\
\hline & Ambivalent NIMBY \\
\hline 2nd preference: & $\begin{array}{l}X \text { is built in my backyard but some } X \text { is also built in someone else's } \\
\text { backyard. }\end{array}$ \\
\hline 3rd preference: & $X$ is not built at all. \\
\hline 4th preference: & $X$ is built only in my backyard. \\
\hline
\end{tabular}


In short, NIMBY payoff structures can resemble those in a prisoner's dilemma, and it is possibly the ambivalent NIMBY who most resembles the image of the 'selfish' NIMBY, because she is not concerned with injustice as long as she benefits from it. The strong NIMBY prefers no wind farms (defection) to any scenario involving her co-operation, and the weak NIMBY prefers to be the sucker to having no RE at all. In a world full of strong NIMBYs and ambivalent NIMBYs, defection would be the dominant strategy. ${ }^{6}$ In a world full of weak NIMBYs, players would not have a dominant strategy, and cooperation would be more likely.

But we must be careful not to confuse our game-theoretic analysis with an ethical analysis: defecting in a strategic game is not the same as acting immorally. Neither should we treat players' preferences simply as a given. One important conclusion to take away from the discussion of NIMBYism as a strategic interaction is that if we want to successfully change outcomes, we need to change preferences. Further down we will discuss in more detail the moral implications of a refusal to host wind farms, and discuss how preferences can be accommodated and modified.

But regardless of whether or not NIMBYism is a kind of prisoner's dilemma, are NIMBYs not aptly described as free-riders? According to Dave Toke, opponents to wind farm developments (and comparable projects) do not want to contribute to a common good that they acknowledge to be desirable and from which they are happy to benefit. He argues that "[t]here is a great temptation for people to act as "free riders", continuing to consume polluting energy sources but making little effort to support what they may perceive to be clean energy sources' (2002: 89). ${ }^{7}$ Bell et al. and Toke suggest that local opposition to wind farms is immoral: after all, free-riding on the contributions of others to a public good is unfair. Opposing wind farms (or other renewable energy plants) in one's vicinity would then be a refusal to contribute to the public good of clean energy.

6. Here is an exemplary game between an ambivalent NIMBY and a non-NIMBY:

Table 6. Exemplary payoffs (ambivalent NIMBY and co-operative non-NIMBY).

\begin{tabular}{|l|c|c|}
\hline & Non-NIMBY co-operates & Non-NIMBY defects \\
\hline Ambivalent NIMBY & $\mathbf{5 0 / 1 0 0}$ & $\mathbf{- 5 0 / 2 5}$ \\
co-operates & $\mathrm{R} / \mathrm{R}$ & $\mathrm{S} / \mathrm{T}$ \\
\hline Ambivalent NIMBY & $\mathbf{1 0 0 / 2 5}$ & $\mathbf{0}-\mathbf{5 0}$ \\
defects & $\mathrm{T} / \mathrm{S}$ & $\mathrm{P} / \mathrm{P}$ \\
\hline
\end{tabular}

The ambivalent NIMBY's dominant strategy is to defect in this game, but the non-NIMBY co-operates. If she were playing against another ambivalent NIMBY, both have 'defect' as their dominant strategy (just like the prisoners), and no wind farms (or other projects) would go ahead.

7. Crozier and Hajzler (2010) also discuss the possibility of NIMBYs being free-riders. 
What is meant by 'public good' here? The literature on public goods has produced several definitions of them. Yet one aspect seems to be central to most accounts of public goods: a public good is a good that is in joint supply to a certain group (Cullity, 2008: 9). Economists define a pure public good as one satisfying two conditions: non-rivalry in, and non-exclusion from, consumption. Once a public good is supplied, one person's consumption of that good does not detract from another person's consumption of the same, and one cannot exclude others from consuming it or benefiting from it.

It is generally assumed that individuals are under some kind of moral obligation to contribute their fair share to such goods, and that free-riding on other people's contributions is unfair. The prototypical free-rider on public goods is the fare-evader, whose refusal to pay for a train ticket is seen as unfair even if his failure to contribute does not diminish the good in question (Cullity, 1995, 2008). ${ }^{8}$

But clean renewable energy is not an existing public good, because it is not in joint supply in any industrialised country (with the exception, perhaps, of Iceland ${ }^{9}$ ). At best, we are in the process of establishing or creating this morally important good. Free-riders are commonly framed as someone taking advantage of an existing or established good without contributing to it. Because the free-rider does not normally diminish the good in question, it is difficult to explain what exactly is wrong with free-riding. NIMBYs, by contrast, do jeopardise the good in question. Protests may delay the shift to RE, or simply diminish the proportion of energy that is renewable or clean. But even if NIMBYs are not free-riders on a public good that is in joint supply, they could still be seen as (wrongfully) refusing to participate in the production of this desirable public good.

This is the angle from which the 'wrongness' of NIMBYism will be discussed in the next section, using the example of wind farm siting. The discussion will reveal that focusing on distributive justice alone is insufficient, because (some of) the burdens arising from the erection of wind farms cannot be justly shared or compensated. We must turn to procedural justice.

8. A lack of partiality is not wrong per se. As Feldman ad Turner (2010: 256-260) point out, partiality and a lack of impartiality are not necessarily unjustifiable. According to Cullity, it is the lack of appropriate standards of impartiality that makes the free-rider's actions unfair. Cullity's account is compatible with the view that some partiality in one's decisions is not only acceptable, but an integral part of a good life.

9. According to the 2012 Iceland Energy Statistics published by Orkustofnun, the National Energy Authority, one hundred per cent of Iceland's electricity came from geothermal sources or hydropower. See Orkustofnun (2012). 


\section{DO NIMBYS FAIL TO CONTRIBUTE THEIR SHARE?}

Even if people who oppose RE developments such as wind farms in their vicinity do not free-ride on an existing good, their resistance still seems to jeopardise the production of several highly desirable public goods: a clean domestic energy regime, and global emissions reductions as a necessary condition for a stable climate (Diesendorf, 2010; Jamieson, 2011; Schwenkenbecher, 2014; Shue, 2005). ${ }^{10}$

In addressing this question, I will focus on NIMBYs concerned with wind farms for several reasons: wind energy is a crucial component of most roadmaps for transitioning to RE, there has been significant protest around siting decisions, and there has been extensive research into protesters' motivations and conflict-resolution strategies. Most of what will be said, however, applies to other RE technologies too.

From the outset, it is important to note that wind farm sites need to be carefully chosen, and not many locations qualify as ideal wind farm spots. Selecting the right location for wind farms is essential for providing high levels of energy security. Installing wind farms in locations where the impact on humans is minimised but efficiency is compromised imposes additional burdens on all, jeopardises the reliability of the energy supply, and potentially compromises the aim of shifting swiftly and completely away from fossil fuels.

Costs associated with such a shift should be distributed as fairly as possible. ${ }^{11}$ But what exactly are the burdens of implementing renewable energy, which must be fairly distributed? Some of these are economic burdens, such as increased electricity prices, which affect all those connected to the grid (though not all of them equally). But there are also burdens that only affect people living in the vicinity of RE plants.

Burdens imposed by wind farms include the audible noise generated by rotor blades and the visual impact that turbines have on the landscape. ${ }^{12}$ According to the German Advisory Council on Global Change, '[p]rovided

10. I am assuming it to be true that the shift to renewable energy is morally mandatory as a means of mitigating climate change. Immediate and comprehensive action is warranted above all for historical emitters and high-emission nations (see, for instance, Shue, 2011; UNEP, 2011) and the refusal to co-operate now is likely to be irreversible (Miller, 2011; Schwenkenbecher, 2013). I am also assuming that achieving one hundred per cent renewable energy supply is achievable (Diesendorf, 2010). Expert opinions differ on the viability and capacity of the low-emission and zero-emission technologies that are currently available, but these differences concern merely the timeframe within which conventional energies can be completely replaced by low-emission and zero-emission technologies; they do not usually doubt that this substitution is feasible.

11. For instance, if the cost of the transition to more renewable energy is paid through a special 'green' tax or through spending cuts in other sectors of the economy, caution should be taken to ensure that taxes are not regressive and that spending cuts do not affect mostly those who are already worse-off (Ekins and Dresner, 2004).

12. There is also an impact on local fauna; see, for instance, Baisner et al. (2010). 
adequate distances to settlements are maintained, noise emissions from modern wind power plants are ... no longer a problem' (WBGU, 2003: 64). In other words, noise pollution can easily be avoided, and will only pose a burden on the local population if regulations concerning minimum distances are not observed. Health problems have been alleged to result from inaudible infrasound caused by the rotation of turbine blades; but several studies suggest that these allegations lack evidence, and that health problems such as the so-called 'wind turbine syndrome' are not the result of the impact of the infrasound as such (AGO/AWEA, 2004). Rather, it seems that the syndrome is a condition resulting from anxiety surrounding wind turbines (see the 2010 NHMRC study in Hall et al., 2012).

One of the most profound impacts of wind farms, however, cannot be easily mitigated: their visual impact on the landscape. Wind farms often significantly alter the visual composition of their surroundings. They usually feature prominently in the landscape and are visible from large distances. Cowell et al. write that

[i]t is undeniable that visual and landscape impacts of wind turbines greatly affect public responses to them, especially where they are seen as violating valued qualities such as openness, quietness and absence of technological structures, but there is boundless scope to dispute the significance of those impacts. (2012: 5)

\section{They continue:}

Wind energy facilities do create impacts that are widely seen as significant and adverse - even if the effects are often sensory rather than toxic. By their nature, wind farms can gravitate towards spaces valued for their openness. The fact that most governments go to great lengths to protect special landscapes (like National Parks) from major industrial developments like wind farms is, in some way, a recognition of the potential of such facilities to harm particular environmental qualities. (2012: 6)

Landscape impacts constitute a burden on local stakeholders to the extent that they diminish or degrade something that is valuable to them. Landscapes - just like certain natural monuments, buildings or streetscapes - may be of cultural, historical or spiritual value, holding significance for communities and individuals. We should therefore consider concerns about the preservation of particular landscapes to be legitimate concerns in principle. ${ }^{13}$

Henceforth, I will focus on the visual or aesthetic impacts of wind farms as the most substantial burden they impose on local residents, because it cannot be mitigated and is necessarily unequally distributed. Only some communities

13. In a similar vein, Feldman and Turner argue that NIMBYs may be expressing what they call geographical partiality: 'Importantly, partiality to place is not in itself a form of selfishness, and it need not mean that the person's ... motivation for caring about the place is self-interest'. They add that 'NIMBY claims typically express a special concern for a particular place' (2010: 256). 
will be thus affected, and it will often be those communities that are already at a disadvantage (see also Cowell et al., 2012: 7; and Bell et al., 2005). The (morally relevant) burdens resulting from visual impact cannot be other than unequal: by their nature they have to be carried by some and not by others. Should they be borne regardless? Could NIMBYs argue on the basis of unfairness that they need not accept wind farms (or RE developments generally) in their vicinity?

Generally speaking, where something morally important is at stake, unfairness in the distribution of burdens need not undermine a moral obligation. If coincidence puts person $A$ rather than person $B$ in a position to help prevent a morally bad outcome at some acceptable cost, then $A$ may not refuse help merely because she must bear this burden unilaterally while $B$ is 'lucky' to have no obligation to help or bear the costs. Similarly, if both $A$ and $B$ could each prevent the same bad outcome, but the required action can be performed by one person only, none of them may simply refuse help on the basis of unfairness.

The visual burdens imposed by wind farms will be borne by those living near suitable sites, while others will be spared. But this fact alone is no legitimate reason to refuse to host wind farms. After all, something morally important is at stake: the public good of clean energy and the substitution of conventional fossil-fuel-based energy technologies with renewable energy technologies. ${ }^{14}$ An agent who unilaterally provides help, however, may often qualify for compensation of the loss suffered. Similarly, wind-farm communities may qualify for compensation from the remaining communities, even more so since the latter will benefit from clean energy generated by wind farms. ${ }^{15} \mathrm{I}$ will come back to this point in a moment.

According to Maarteen Wolsink, NIMBYs regularly appeal to fairness- or justice-related reasons:

Local opposition cannot be explained by the egotistical motives of local residents. When the inclination to behave according to (supposed) backyard motives is investigated, the scale to measure this phenomenon appears to indicate commitment to equity issues and fairness of decision-making. Hence, for wind power, local involvement to represent the local values of site-specific landscapes is crucial. For other renewables the source-specific features are different, but conflicts can be expected as well because the fairness of implementation decisions will be equally significant. (2007: 2692)

14. Sometimes the failure of a key RE project can be in an important sense irreversible: it can lock in fossil-fuel-based energy technology for decades to come, making it ever harder to shift to renewables. Similarly, some of the other effects of slowing down the shift to renewables are irreversible. A delayed shift will mean a greater total amount of harmful emissions, as well as of local co-pollution associated with conventional fossil-fuel-based energy generation.

15. This is assuming that the benefits of clean energy will be available to all. 
Wolsink argues that NIMBYs often view themselves as victims of an injustice; ${ }^{16}$ they have to carry a disproportionate share of a burden that decision-makers have shifted onto them without consultation. They argue that they should be engaged in planning decisions that will impact on their lives and well-being. Is their refusal to contribute to the common good a refusal to endure unfairness for the sake of what is overall morally mandatory? If so, it seems that where communities are granted economic compensation for the visual impacts of wind farms (or where these burdens are mitigated or minimised), they are no longer justified in refusing to accept them in their vicinity. Or are they?

It is important to qualify this claim in two ways. First, it depends on the level of burden imposed on such communities, and the nature of their refusal to allow wind farms in their vicinity. In some cases, the aim of one's refusal to co-operate in the production of a common good is to enforce standards of fairness; in others, it is a categorical refusal. A categorical refusal may be justified for a community that lives off tourism, as the integrity of the surrounding natural landscape is essential to its economic wellbeing. Second, it is not clear that all burdens can be compensated. When Cowell et al. write that, where possible, local communities should be compensated for the loss of 'environmental qualities that people might otherwise have expected to keep' (2012: 12), the question arises: to what extent it is even possible to compensate the loss of environmental qualities such as negative visual impacts on valued landscapes? Without claiming that all - or even most - NIMBYs are concerned with landscape values, the fact that protests can be about the loss of landscapes reveals a difficulty of the compensation approach, and, in fact, of the distributive justice approach as such.

In approaching NIMBYism as a problem of distributive justice - as protests against an unequal distribution of costs and burdens - compensation schemes appear to be the obvious solution. This perspective, however, may (partially) miss the point. When an object is irreplaceable, it is not possible to fully compensate people for its loss (see, for instance, Goodin, 1989: 73). Landscapes, in fact, are irreplaceable. If Bell et al. (2005) and Wolsink (2007) are correct, then concerns about the preservation of a particular landscape are at the heart of many protests against projects like wind farms. Often, people do not want to be compensated for the loss of a valued landscape, rather they want to preserve it. This reveals a completely new dimension of the problem discussed here. While economic disadvantages can be compensated, loss of landscapes possibly cannot. Are preservation concerns sometimes incompatible with the obligation to shift to clean energy? And if so, how should we reconcile them?

16. Whether their complaints are legitimate would depend on several factors, including on whether or not affected communities are already disadvantaged. Economically disadvantaged communities are more vulnerable and are therefore often targeted as potential sites for wind farms and other schemes (Bell et al., 2005: 473). Ironically, more affluent communities are usually better equipped for effectively opposing such schemes than less affluent ones (see also Feldman and Turner, 2010: 263ff.). 
One way to account for such concerns is simply to stipulate the overriding importance of shifting to RE: if impacts on valued landscapes are the only way of achieving the shift, then some of us will just have to bite the bullet. But perhaps there are other ways to address potential conflicts between both concerns. Bell et al. have argued that "there is no "technical fix" for the problem of landscape impact', and that '[i]nstead, the only way of accommodating people's landscape concerns is to site wind farms in places that people find more acceptable' (2005: 470). They suggest that we need to approach the problem as one of procedural justice. In the following section, I show that we need procedures that allow for non-standard decision-making.

\section{MORE THAN A MATTER OF DISTRIBUTION?}

How should landscape values figure in decision-making about the siting of wind farms? In this section, I argue that we have to abandon the idea of ranking and trading off competing concerns. Rather than merely engaging stakeholders in a process where they can express their (pre-conceived) set of preferences and include those preferences in siting decisions, we should start thinking about community engagement as a process that permits preferences to be formed and adjusted. As I will explain further down, non-traditional accounts of rational choice may be best suited to solving the kind of conflicts in question.

The standard way to solve conflicts of competing concerns (and obligations) is to trade off one concern against the other, thus establishing which concern is in relative terms more important: for instance, that of transitioning to renewable energy, or that of preserving a particular landscape valuable to a particular group of NIMBYs. The trade-off approach compares and ranks the options available. This does not mean that the landscape concerns will go unheard; the ranking can account for them:

Table 7. Ranking of concerns. ${ }^{17}$

\begin{tabular}{|l|l|}
\hline Best option: & RE is implemented and valued landscapes are preserved. ${ }^{18}$ \\
\hline Second-best option: & RE is implemented without the preservation of valued landscapes. \\
\hline Third-best option: & RE is not implemented and valued landscapes are preserved. \\
\hline
\end{tabular}

17. According to Claire Haggett (2010: 314), it is important to distinguish between NIMBYs, who are concerned with impacts on their place of residence and therefore face a personal sacrifice, and protesters, who want to preserve far-away landscapes. Feldman and Turner, however, are quite right to point out that 'one can have NIMBY style preference rankings with respect to places that are far from one's current home' (2014: 107). I would add that individual well-being may well be impacted by the destruction of valued far-away landscapes. 
The underlying assumption of this approach is that there is a single umpiring principle or priority-rule, which establishes how options rank in comparison. If a transition to RE is significantly more important than landscape concerns, the former will trump the latter whenever a choice must be made between these two. But is the former more important than the latter in every single instance? Or is there something wrong with this approach as such?

The immediate worry is that landscape concerns can easily be construed as detrimental to RE implementation. Efforts to preserve landscapes will usually impose (additional) costs on the process of RE implementation: for example, the cost of having to find an alternative - equally suitable - location, or the cost of constructing a wind farm in a less suitable location where it generates less energy or does so less reliably. Assuming that implementing RE is not only morally important but also urgent, such costs can almost always be understood as undermining the aim of a timely implementation of RE. The worry is that in this trade-off, landscape concerns are likely to lose out against RE developments in most cases. Clearly, the good done by a shift to clean energy, and the mitigation of dangerous climate change, outweighs the importance of individual landscapes. Or does it?

Several authors have criticised the trade-off approach to environmental decision-making arguing that it wrongly assumes value commensurability (see O'Neill, 1998; O'Neill et al., 2008). They maintain that the values attached to landscapes and our natural environments may be incommensurable with the values promoted by renewable energies, including those values that climate change mitigation helps us protect. They have argued that the expression of concerns for valued landscapes in the form of NIMBYism may sometimes constitute an instance of resisting the logic of commensurability. ${ }^{18}$

O'Neill has argued that 'the major source of assumption of commensurability in economics lies in the supposition that the rational resolution of practical conflicts requires a common measure through which different options can be compared' (1998: 122). He not only thinks that practical conflict can be solved without such a common measure, but also argues that contemporary accounts of cost-benefit analysis make a mistake in assuming that there must exist one method for solving any practical conflict if such conflict-solving is to be rational. O'Neill argues that rationality does not require a single general umpiring rule, ${ }^{19}$ instead of commensurability, all that is needed is a weak

18. In a similar vein, Martin Drenthen argues that '[m]any NIMBY protests cannot be solely seen as attempts by local inhabitants to promote their interests and preference in the political arena. The more radical issue is another: whether the place at stake in all its particularity is a particularly valuable, meaningful place, not to be compared to or replaced by other places' (2010: 323).

19. To say that it does, involves an invalid shift in the scope of a quantifier (O'Neill, 1998: 123):

$\boldsymbol{U E}$. For any putative practical conflict, rationality requires that there be a way of resolving the conflict.

However, it does not follow that a single general umpiring rule is required: 


\section{WHAT IS WRONG WITH NIMBYS?}

comparability of goods. ${ }^{20}$ This means that even if some values are incommensurable, we can still arrive at solutions to value-conflicts. The idea is that it is precisely the exercise of practical judgement in particular contexts which helps us resolve such conflicts. The way we resolve them, though, may not be transferable from one context to another. Importantly, we need not make a judgement of the form that one consideration is always more important and overrides another consideration. In different contexts, values may have more or less weight, depending on the circumstances.

So how should we decide between competing moral imperatives? Let us have a look at the following example: Assume that we must choose between three different wind farm sites $\mathrm{A}, \mathrm{B}$ and $\mathrm{C}$, which have different strengths:

- Mitigation and clean energy impact: The site's energy capacity and as a result the extent to which it contributes to substituting fossil fuel based energy generation;

- Efficiency: The forecast energy output in relation to construction and running cost; and

- Landscape impact.

Table 8. Competing moral imperatives.

\begin{tabular}{|c|c|c|c|}
\hline Location & Mitigation impact & Efficiency & Landscape impact \\
\hline$A$ & $1 \mathrm{st}$ & $2 \mathrm{nd}$ & $3 \mathrm{rd}$ \\
\hline$B$ & $2 \mathrm{nd}$ & $3 \mathrm{rd}$ & $1 \mathrm{st}$ \\
\hline$C$ & $3 \mathrm{rd}$ & $1 \mathrm{st}$ & $2 \mathrm{nd}$ \\
\hline
\end{tabular}

- It is rational to prefer $A$ over $B$, because $A$ has the biggest mitigation impact and is more cost efficient than $B$;

- It is rational to prefer $B$ over $C$, because $B$ 's impact on the landscape is smaller and it has a higher mitigation impact;

- It is rational to prefer $C$ over $A$, because $C$ is more efficient than $A$ and has a less severe impact on the landscape.

$\boldsymbol{E} \boldsymbol{U}$. Rationality requires there be a method such that for any practical conflict the method resolves the conflict (ibid.: 123).

The inference from UE to EU involves a shift in the scope of the quantifiers from

UE. $\forall c \exists m R m c$

to

EU. $\exists m \forall c$ Rmc.

20. O'Neill defines 'weak comparability' like this: 'at any time $\mathrm{t}$ in context $\mathrm{c}$ given a putative practical conflict of goods there is a way of comparing the different goods to arrive at an outcome that resolves the conflict ... We exercise practical judgement in a particular context to resolve conflicts between different values which present different standards and measures of value' (1998: 124). 
If equal weight is assigned to all three considerations, then these preferences will be intransitive without any failure of rationality. In order to come to a decision, we must rank the options. According to O'Neill, this need not be a ranking of values valid for all possible conflicts and which can resolve the conflict in advance (1993: 113). Rather, the weight given to the different considerations is specific to that context and conflict. What would this mean if applied to wind farm cases? Should affected residents simply decide in each particular case which of these values is most important to them? But then would NIMBYS not always argue that landscape is the most important concern, and therewith jeopardise a shift away from fossil fuels or even end up with highly inefficient (and thus expensive) wind farms, as in option B above? How can we decide what to do when both are in conflict?

The first lesson to take away from O'Neill is that the relative importance of competing concerns can be decided on a case-by-case basis. The second lesson is that we need to abstain from adopting substantive overriding principles or values when assessing the outcome. The rational choice where claims compete need not be the best outcome given existing preferences or values.

Non-substantive accounts of rational decision-making - including procedural, expressive and narrative accounts of rationality - may solve this kind of problem, because they do not define rational choice in terms of the best outcome. According to procedural accounts of practical reason, an action is rational if it is an outcome of a rational procedure, for example when it is the outcome of appropriate deliberation. ${ }^{21}$ Preferences are 'formed and transformed through reasoned dialogue between free and equal citizens' (O'Neill, 2007: 13). O'Neill et al. suggest that environmental decisions should be made in a way that is procedurally rational, rather than substantively rational, to account for plural and incommensurable values (2008: 205). ${ }^{22}$

According to expressive accounts, actions are rational where they express the agent's evaluations of objects and persons. The idea is that '[a]ctions are not just instrumental means to an end, but a way of expressing attitudes to people and things' (O’Neill, 1998: 126). Consequently, to act rationally means to express one's evaluations, to express the relative importance we attach to the things evaluated.

Narrative accounts of rational choice go one step further in emphasising that choices in human lives 'are a matter of deciding not simply some

21. O'Neill argues that ' $\mathrm{r}]$ ational behaviour is that which emerges from deliberation that meets the norms of rational discussion. Given a procedural account of rationality, what matters is the development of deliberative institutions that allow citizens to form preferences through reasoned dialogue, not institutions for aggregating given preferences to arrive at an "optimal" outcome' (1998: 126).

22. O'Neill et al. (2008: 204) compare procedural accounts to substantive accounts of rational choice (decision-making as the result of aggregating the existing preferences of citizens), and argue that in the presence of plural and incommensurable values, the former present a better way of rational decision-making. 
maximisation of valued items, but of how the story of a life of a person or community should continue' (O'Neill, 1993: 127). Situations in which values conflict and in which we nevertheless must decide between two courses of action can change us as agents forever (Raz, 1986: 339-340). Hence the choice that we make does not so much reflect who we are and what values we hold, but who we want to be or will be.

Let us now return to the problem of NIMBYism and practical decisionmaking under the assumption of value-incommensurability. Adopting non-substantive accounts of rationality in order to solve the conflict in question would involve allowing for the right kind of deliberation, in the process giving stakeholders the opportunity to adjust or change their values, or simply to express them, or else to choose a certain narrative over another. Decision-making is then 'not a matter of calibrating losses and gains on various values according to some measure, and then deciding which produces the highest total value. It is rather a matter of attending to different reasons and forming a judgement through the process of deliberation' (O'Neill et al., 2008: 205).

Such a process may be applied to all relevant considerations (for example: mitigation impact, landscape impact or efficiency), or only to some. If such an approach is adopted in the decision-making process, the conflict may or may not be resolved in favour of the threatened landscape.

But this might make RE advocates nervous. They could argue that for local stakeholders it may seem that landscapes should take priority in most cases, but from a national and global perspective, the necessity to shift to clean energy and to mitigate climate change clearly overrides such concerns (especially given that valued landscapes would be threatened by climate change too). We seem to be faced with a similar worry to the one with which we started: that which is individually rational and that which is collectively rational simply differ.

One possible solution is to argue that the collective rationale should outweigh the individual one in one regard: 'mitigation impact' must be the overriding concerns in such decisions, but the relative importance of the remaining criteria (efficiency and landscape value) is to be determined for each individual case by non-substantive rational decision-making. ${ }^{23}$ But this would perhaps not satisfy NIMBYs: in some cases, it seems that mitigation and

23. Here is an example for limiting the use of non-substantive rational choice in siting decisions. If mitigation impact was the most important consideration, and if several sites had the same mitigation impact, we could allow for the relative importance of efficiency considerations and landscape impact to be decided in a non-standard way:

Table 9. Competing moral imperatives.

\begin{tabular}{|c|c|c|c|}
\hline Location & Mitigation impact & Efficiency & Landscape impact \\
\hline$D$ & $1 \mathrm{st}$ & 2nd & 3rd \\
\hline$E$ & $1 \mathrm{st}$ & $3 \mathrm{rd}$ & $2 \mathrm{nd}$ \\
\hline
\end{tabular}


clean-energy concerns should not trump landscape preservation. Is there no better solution then?

There is at least some reason to think that we actually can (or perhaps even must) have both: plural (incommensurable) values, and a shift to RE. And here is how: several authors suggest that engaging local stakeholders regularly changes their attitudes towards RE projects (Cowell et al., 2011; Murphy, 2010; Warren and McFadyen, 2010). Catherine Gross (2007) finds that people are more accepting of siting decisions if they perceive the process leading to the decision as fair. People's concerns regarding landscape impacts of wind turbines can be addressed directly via extensive community consulting on turbine placement during which important viewpoints should be agreed with the community early in the process (AGO/AWEA, 2004; AWEA/ACNT, 2007).

Moving beyond mere consultation of stakeholders, community ownership has been shown to have a significant positive impact on the acceptance of wind farms, essentially giving communities control over the process (Murphy, 2010). But what is perhaps more surprising is that, according to Warren and McFadyen (2010), where communities and individuals have been engaged in the decision-making process and where they financially benefit from them, local residents perceive wind farms as positive, including their visual impact on the landscape.

In short, empirical evidence seems to suggest that stakeholder engagement and procedures that allow for non-standard decision-making will eventually play in favour of a shift to renewables. It seems that people are just not that concerned with wind farms if they consider them 'their own' project. Not only can community consultation ensure that wind turbines are erected where they least disturb local residents, but it seems that if locals become decision-makers or even co-owners, they find them less aesthetically objectionable. The practical conflict between conservation and mitigation concerns therefore seems - at least in principle - resolvable. To the extent that values change during such processes, the theoretical conflict as to which concern is morally weightier will be resolved, too.

The more general conclusion for controversial infrastructure projects seems to be that community consulting should not be seen merely as a tool for increasing the sense of fairness, or for finding ways to distribute benefits and burdens as justly as possible, but as a way of allowing people to adjust, or else develop, their collective and individual preferences and beliefs, and to take control over the process.

\section{CONCLUSION}

To conclude, let me return to our initial question: what is wrong with NIMBYs? This article suggests that sometimes there is nothing wrong with them at all. 
NIMBYs may be expressing concerns for a particular landscape which they value, and on which they may sometimes legitimately refuse to put a price tag. Their refusal to co-operate in the transition to renewable energy may reflect both a lack of procedural and distributive justice. Acknowledging that at least some of these tensions arise from true conflicts of value might help us to better understand NIMBYism and, in fact, give us a better idea of how we might possibly overcome it. In both cases - the resistance against unjust distribution of burdens, and the resistance against landscape alterations - successful responses will seek to involve affected local populations in the decision-making process.

What I have not argued, however, is that all - or even a particularly large number of - NIMBY claims are legitimate in the way described above; only that, in principle, they can be. Even the less legitimate NIMBY claims, however, are likely to be more successfully addressed by way of providing economic incentives to communities and involving them in the decision-making process. In fact, because local resistance to renewable energy developments delays emission reductions and prevents countries from complying with climate change mitigation duties, both prudential and moral reasons speak in favour of seeking the dialogue with concerned stakeholders.

\section{ACKNOWLEDGEMENTS}

Research for this article was partly undertaken in the context of the 'Zero Carbon Australia and Social Justice' project with the Social Justice Initiative at the University of Melbourne (2012-2013). The author would like to thank Jeremy Moss for helpful discussions concerning the topic of this article and David Butler for commenting on an earlier draft. She is also grateful to two anonymous referees for Environmental Values for their very helpful and encouraging feedback.

\section{REFERENCES}

Australian Greenhouse Office and Australian Wind Energy Association [AGO/AWEA]. 2004. 'Wind Farm Fact Sheets'. Online at www.auswind.org (accessed 5 July 2017).

Australian Wind Energy Association and Australian Council of National Trusts. 2007. 'Wind Farms and Landscape Values; National Assessment Framework; Foundation Report'. Melbourne: Australian Wind Energy Association.

Baisner, A.J., J.L. Andersen, A. Findsen, S.W. Yde Granath, K.O. Madsen and M. Desholm. 2010. 'Minimizing collision risk between migrating raptors and marine wind farms: development of a spatial planning tool'. Environmental Management 46(5): 801-808. Crossref 


\section{ANNE SCHWENKENBECHER}

Bell, D., T. Gray and C. Haggett. 2005. 'The "social gap" in wind farm siting decisions: explanations and policy responses'. Environmental Politics 14(4): 460-477. Crossref

Cowell, R., G. Bristow and M. Munday. 2011. 'Acceptance, acceptability and environmental justice: the role of community benefits in wind energy development'. Journal of Environmental Planning and Management 54(4): 539-557. Crossref

Cowell, R., G. Bristow and M. Munday. 2012. 'Wind energy and justice for disadvantaged communities'. Joseph Rowntree Foundation. Online at: http:/www. hoylakevision.org.uk/wp-content/uploads/2012/11/wind-farms-communities-summary.pdf (accessed 5 July 2017).

Crozier, G.K.D. and C. Hajzler. 2010. 'Nimby claims, free riders and universalisability'. Ethics, Place \& Environment 13(3): 317-320. Crossref

Cullity, G. 1995. 'Moral free riding'. Philosophy and Public Affairs 24(1): 3-34. Crossref

Cullity, G. 2008. 'Public goods and fairness'. Australasian Journal of Philosophy 86(1): 1-21. Crossref

Diesendorf, M. 2011. 'Redesigning energy systems'. In D. Schlosberg, R.B. Norgaard and J.S. Dryzek (eds), The Oxford Handbook of Climate Change and Society, pp. 561-580. Oxford: Oxford University Press. Crossref

Drenthen, M. 2010. 'NIMBY and the ethics of the particular'. Ethics, Place \& Environment 13(3): 321-323. Crossref

Ekins, P. and S. Dresner. 2004. 'Reducing the impact of "green" taxes and charges on low-income households'. Joseph Rowntree Foundation. Online at: http://www.psi. org.uk/pdf/2004/greentaxesandcharges.pdf (accessed 5 July 2017).

Feldman, S. and D. Turner. 2010. 'Why not NIMBY?' Ethics, Place \& Environment 13(3): 251-266. Crossref

Feldman, S. and D. Turner. 2014. 'Why not NIMBY?' Ethics, Policy \& Environment 17(1): 105-115.

German Advisory Council on Global Change [WBGU]. 2003. 'World in transition: towards sustainable energy systems'. Online at: http://www.wbgu.de/fileadmin/ user_upload/wbgu.de/templates/dateien/veroeffentlichungen/hauptgutachten/ jg2003/wbgu_jg2003_engl.pdf (accessed 5 July 2017).

Goodin, R.E. 1989. 'Theories of compensation'. Oxford Journal of Legal Studies 9(1): 56-75. Crossref

Gross, C. 2007. 'Community perspectives of wind energy in Australia: the application of a justice and community fairness framework to increase social acceptance'. Energy Policy 35(5): 2727-2736. Crossref

Haggett, C. 2010. 'Why not NIMBY? A response, reviewing the empirical evidence'. Ethics, Place \& Environment 13(3): 313-316. Crossref

Hall, N., P. Ashworth and H. Shaw. 2012. 'Exploring community acceptance of rural wind farms in Australia: a snapshot'. CSIRO 'Science Into Society' Group. Online at: http:// communityrenewables.org.au/wp-content/uploads/2013/02/CSIRO_Acceptance-ofrural-wind-farms-in-Australia_2012_Summary.pdf (accessed 5 July 2017).

Hermansson, H. 2007. 'The ethics of NIMBY conflicts'. Ethical Theory and Moral Practice 10(1): 23-34. Crossref 


\section{WHAT IS WRONG WITH NIMBYS?}

Intergovernmental Panel on Climate Change [IPCC]. 2011. Special Report on Renewable Energy Sources and Climate Change Mitigation. New York, NY: Cambridge University Press.

Jamieson, D. 2011. 'Energy, ethics, and the transformation of nature'. In D.G. Arnold (ed.), The Ethics of Global Climate Change, pp. 16-37. Cambridge, UK: Cambridge University Press. Crossref

Miller, D. 2011. 'Taking up the slack? Responsibility and justice in situations of partial compliance'. In C. Knight and Z. Stemplowska (eds), Responsibility and Distributive Justice, pp. 230-245. Oxford: Oxford University Press. Crossref

Murphy, J. 2010. 'At the edge: community ownership, climate change and energy in Scotland'. Joseph Rowntree Foundation. Online at: https:/www.jrf.org.uk/sites/ default/files/jrf/migrated/files/community-ownership-scotland.pdf (accessed 5 July 2017).

O'Neill, J. 1993. Ecology, Policy and Politics: Human Well-Being and the Natural World. New York, NY: Routledge. Crossref

O’Neill, J. 1998. The Market: Ethics, Knowledge, and Politics. New York, NY: Routledge. Crossref

O'Neill, J. 2007. Markets, Deliberation and Environment. London: Routledge.

O'Neill, J., A. Holland and A. Light. 2008. Environmental Values. Abingdon: Routledge.

Orkustofnun. 2012. 'Energy Statistics in Iceland 2012'. Online at: http://www.os.is/ gogn/os-onnur-rit/orkutolur_2012-enska.pdf (accessed 5 July 2017).

Raz, J. 1986. The Morality of Freedom. Oxford: Clarendon Press.

Schwenkenbecher, A. 2013. 'Bridging the emissions gap: a plea for taking up the slack'. Philosophy and Public Issues 3(1): 273-301.

Schwenkenbecher, A. 2014. 'Is there an obligation to reduce one's individual carbon footprint?' Critical Review of International Social and Political Philosophy 17(2): 168-188. Crossref

Shue, H. 2005. 'Responsibility to future generations and the technological transition'. In W. Sinnott-Armstrong and R.B. Howarth (eds), Perspectives on Climate Change: Science, Economics, Politics, Ethics, pp. 265-283. Amsterdam: Elsevier. Crossref

Shue, H. 2011. 'Face reality? After you! - A call for leadership on climate change'. Ethics \& International Affairs 25(1): 17-26. Crossref

Toke, D. 2002. 'Wind power in UK and Denmark: can rational choice help explain different outcomes?' Environmental Politics 11(4): 83-100. Crossref

United Nations Environment Programme [UNEP]. 2011. 'Bridging the emissions gap: a UNEP synthesis report'. Online at: http://www.ecofys.com/files/files/unep_bridging\%20the\%20emissions\%20gap.pdf (accessed 5 July 2017).

Warren, C.R., and M. McFadyen. 2010. 'Does community ownership affect public attitudes to wind energy? A case study from South-west Scotland'. Land Use Policy 27(2): 204-213. Crossref

Wolsink, M. 2007. 'Planning of renewables schemes: deliberative and fair decisionmaking on landscape issues instead of reproachful accusations of non-co-operation'. Energy Policy 35(5): 2692-2704. Crossref 
